\title{
Factors Underlying Defaulting on Antihypertensive Treatment
}

\author{
N Alam ${ }^{1}$, M A Azhar ${ }^{2}$, A W Chowdhury ${ }^{3}, \mathrm{~K} \mathrm{M} \mathrm{N} \mathrm{Sabah}^{4}$, M R Amin ${ }^{5}$
}

\begin{abstract}
The magnitude of hypertensive patient not continuing treatment is not well documented. But it is assumed that it could be worse and thereby would contribute significantly to mortality and morbidity. A study can produce awareness among all level of medical parctitioners regarding the factors underlying defaulting on anti hypertensive treatment. To find out the factors underlying being defaulter of antihypertensive treatment and making future recommendation for remedy - were the main objectives of the present study It was a cross sectional study which was carried out in medical indoor \& out patient department of Sir Salimullah Medical College \& Mitford Hospital, (SSMC \& MH) Dhaka on 100 patients selected by purposive sampling who were defaulters of anti hypertensive treatment. The main causes of becoming defaulters were lack of knowledge
\end{abstract}

\section{Introduction}

Hypertension, the most common cardiovascular disease, is probably the most important public health problem worldwide with global burden of $20 \%$ of the world population. In Bangladesh its prevalence is $20-24 \%$. Regarding unawareness in Bangladesh, $71.6 \%$ of urban and $86.3 \%$ of the rural hypertensive subjects were unaware respectively. ${ }^{1-3}$ Development of many anti hypertensive drugs over the last six decades were huge but economically and therapeutically ideal one not yet has been achieved. Each drug has got some virtue and deficiency for appropriate management of patients. Many management guidelines have been recommended. ${ }^{4-7}$ However the present guideline forwarded by Joint National Committee ( JNC7) ${ }^{8}$ and British Hypertension Society (BHS) and National Institute of Health and Clinical Excellence (NICE) ${ }^{9}$ are being followed across the world including Bangladesh. As a result of extensive educational programs in the late 1960 s and 1970 s by both private and government agencies, the number of undiagnosed and/or untreated patients were reduced significantly by the late 1980 s to a level of about $25 \%$, with a concomitant decline in cardiovascular mortality. Unfortunately, by the mid-1990s, this

1. Dr. Nur Alam Registrar, Cardiology, DMCH.

2. Dr. M A Azhar, Head of medicine dept. and Principal, SSMC \& Mitford Hospital, Dhaka.

3.Dr. Abdul Wadud Chowdhury, Assoc. Prof. of Cardiology, DMCH

4.Dr. KMN Sabah, Asst. Prof. of Cardiology, DMCH.

5. Dr. Md. Rasul Amin, Medical Officer, Cardiology,BSMMU.

\section{Corresponding Author}

Dr. Nur Alam Registrar, Cardiology, DMCH.

email-alamnur28@yahoo.com and misconception (40\%) and financial constrain (32\%). The complications of defaulters of antihypertensive treatment were enormous. Most of the patients (80\%) suffered from major target organ damage like Stroke/TIA (35\%), LVH/LVF/IHD (15\%), Retinopathy (12\%), Nephropathy (5\%) and more than one organ damage (13\%). Awareness both of physicians and public about hypertension and proper counseling with education and information about hypertension, rational use of medication and regular follow up will be helpful to avoid morbid complication.

beneficial trend began to wane. The number of undiagnosed patients with hypertension increased to nearly $33 \%$, the decline in cardio vascular mortality flattened, and the number of individuals with chronic diseases with untreated or poorly treated hypertension increased. ${ }^{10}$ In Bangladesh a few studies have been conducted to see the prevalence, causes and complications of hypertensive patients who are defaulter (patients, previously diagnosed as hypertensive but not taking or inadequately taking treatment). ${ }^{11}$ Since there is lack of works in these fields, such study can produce awareness among all level of medical practitioners regarding consequences of defaulting and enhance proper treatment approaches \& enriches future recommendations.

\section{Materials and methods}

This cross sectional study was carried out in medical indoor \& out patient department of Sir Salimullah Medical College \& Mitford Hospital, (SSMC \& MH) Dhaka on 100 patients who were defaulters of anti hypertensive treatment,during the period of October 2007 to February, 2008. Sample was taken purposively Previously diagnosed hypertensive patients (systolic $\geq$ $140 \mathrm{mmHg}$ and/or diastolic $\geq 90 \mathrm{mmHg}$ ), not taking treatment or irregularly taking treatment or inadequately taking treatment. Exclusion criteria were patients not giving consent, patients dropped out before investigations were completed or before full diagnoses were made Detailed history, thorough clinical examination including fundoscopy were performed.Following investigations were done in all patients: routine blood examination, chest X-ray P/A view, ECG, urine R/M/E, blood sugar, blood urea $\&$ serum creatinine, fasting lipid profile. Other investigations were done on selected cases like Echocardiography, ETT, urinary total protein, urinary albumin creatinine ratio, CT scan of brain, USG of whole abdomen, serum electrolytes, serum T3, T4, TSH, serum cortisol etc. Informations were collected by the author through preformed questionnaire. 
Table- I: Age distribution of defaulters of anti hypertensive treatment $(n=100)$.

\begin{tabular}{|ccc|}
\hline Age group (Years) & Number of subjects & Percentage (\%) \\
2534 & 1 & 1 \\
3544 & 9 & 9 \\
4554 & 14 & 14 \\
5564 & 26 & 26 \\
6574 & 40 & 40 \\
$>75$ & 10 & 10 \\
\hline
\end{tabular}

Table-II: Sex distribution of defaulters $(n=100)$.

\begin{tabular}{|ccc|}
\hline Sex & No. of patient & Percentage (\%) \\
Male & 75 & 75 \\
& & \\
Female & 25 & 25 \\
\hline
\end{tabular}

Table- III: Educational qualification of defaulters $(n=$ 100).

\begin{tabular}{|lc|}
\hline \multicolumn{1}{|c|}{ Educational qualification } & Number (\%) \\
No formal education & $16(16 \%)$ \\
Below SSC & $28(28 \%)$ \\
Above SSC but Under graduate & $32(32 \%)$ \\
Graduate & $24(24 \%)$ \\
\hline
\end{tabular}

Table-IV: Causes of becoming defaulter $(n=100)$.

\begin{tabular}{|lcc|}
\hline \multicolumn{1}{|c}{ Aetiology } & Number & Percentage \\
Lack of knowledge or misconception & 40 & 40 \\
Financial constrain & 32 & 32 \\
Drugs adverse reaction or complications & 26 & 26 \\
Switchover to indigenous drug & 2 & 2 \\
\hline
\end{tabular}

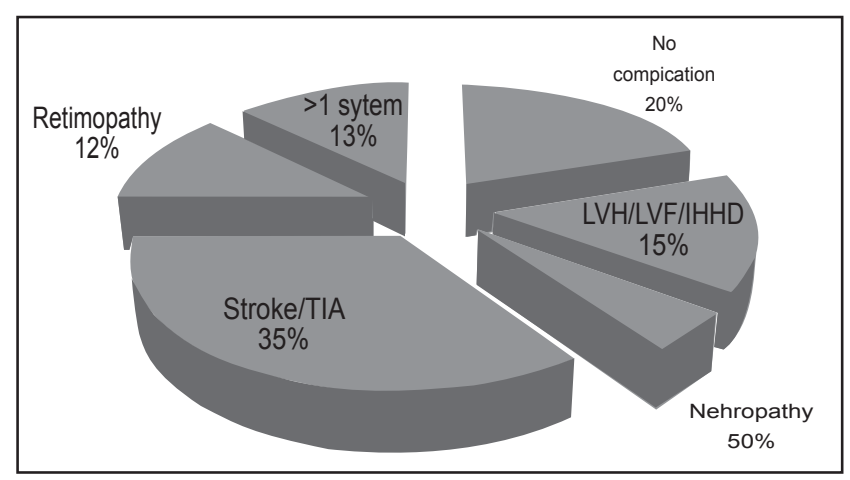

Figure I

\section{Results}

A total of 100 patients were included in the study. Most of the ptatients were between 55-74 years age group (66\%) (Table I). Among the study subjects most of the patients were male $(75 \%)$ with a male to female ratio 3:1 (Table II). The analysis of educational qualifications shows that nearly $60 \%$ of the defaulters had SSC or above level education with only $16 \%$ of the defaulters had no formal education at all (Table III). This study shows that the commonest cause of being defaulters is lack of knowledge or misconception (40\%) and the next is financial constraints $(32 \%)$. (Table IV). However one fourth of patients discontinue drugs for adverse reaction or complications. This study also shows that among the defaulters $80 \%$ had target organ damage. Cerebrovascular disease (Stroke \& TIA) and cardiac disease were the predominant complication (Table-V).

\section{Discussion}

The underlying cause of this scenario of defaulting may vary from country to country. This study was conducted to have an idea about the factors underlying the defaulters of antihypertensive treatment in our country. The age wise distribution of defaulters of anti hypertensive treatment denotes that main mass is elderly people aged $65-75$ years. One important reason for this may be that the severity of the complications of hypertension which bring the patients to the hospital increases with aging. In this study $66 \%$ of patients were 55-75 years age group. This finding correlates with another study done in our country where majority of stroke patients were in between 55 to 75 years (65\%), where hypertension was found to be an important risk factor. ${ }^{11}$ The less number of active age group patients in this study may be due to factors like a) they are more adherent to prescribed treatment, b) they cannot attend hospital during working hour, c) they are more financially able to afford treatment, d) prevalence of hypertension increases after 5th decade of life. A study among school teachers in Sofia, showed that the prevalence of hypertension increases sharply after 45 years of age. ${ }^{12}$ In another study, done at Dormont High School (Pittsburg, Pennsylvania) $)^{13}$ the prevalence of hypertension increases as age increased. Only a broad population based study can reveal the actual age group prevalence of hypertension in our country. However, a hospital based hypertension clinic offering free cost treatment at out of office hours such as late afternoon or evening can bring the so called younger working hypertensive groups for proper treatment. Only then the actual number of defaulters of antihypertensive treatment in the young age groups can be properly evaluated. 
In this study, number of female patients were comparatively less than that of male. One important reason for this difference is that less female patients come to hospital for treatment in our country for various socio-economic reasons. This study shows majority of the defaulter's educational qualification were above HSC level (56\%). So, educated people might become defaulter due to lack of proper motivation. Regarding complications among the defaulters $35 \%$ had neurological, $15 \%$ cardiovascular, $12 \%$ eye, $5 \%$ renal complication and $13 \%$ had multiple organ damage. A study in USA has shown that the prevalence of congestive heart failure from age 55-75 years, more than doubled between 1970-1980 and 1988 to 1991 among the hypertensive who are not adequately treated. ${ }^{13}$ The prevalence of end stage renal disease per million population increases from $<100$ in 1982 to $>250$ in 1995 in USA. ${ }^{14}$ In this study the number of cardiovascular and renal complication among the defaulters of anti hypertensive treatment is $15 \%$ and $5 \%$ respectively. Which is consistent with previous study. ${ }^{14}$ Previously it was shown that, patient with hypertension die prematurely. The most common cause of death is heart disease; stroke and renal failure also frequent, particularly in patient with significant retinopathy. ${ }^{15,16}$ Trying to find out the causes of being defaulter in this study it is interestingly seen that most of the defaulters are due to lack of knowledge or misconception (40\%) and financial constraints 32\%. Drug adverse reaction or development of complication was another very important factor. Poverty is not the number one factor of becoming defaulter. Ignorance, misconception of patient and lack of proper education and motivation by the physicians are perhaps the main reasons. So a lot to be done while treating a hypertensive patient like proper counseling, providing Iinformation, proper motivation and regular follow up etc.

A study done by Waliullah, showed that $98 \%$ people have no awareness of their hypertensive status. ${ }^{17}$

Islam et al. showed that $50 \%$ of the secretariat people of Bangladesh who were found to have hypertension were not aware of their status of hypertension. ${ }^{18}$

Above study results support the findings of this study where lack of knowledge, awareness and misconception found to be the main cause of being defaulter. It is also evident that the scenario has not changed much over the years in our country. All these issues might be overcome by building up a good doctor patient relationship and proper counseling and motivation.

\section{Conclusion}

The number of defaulters of anti hypertensive treatment contributing to morbidity and mortality is high and alarm ing and several factors contributed for patients being defaulters. Awareness both of physicians and public about hypertension could prevent the development of complications and thereby ameliorating the sufferings of the patients. Proper counseling with education and information about hypertension, rational use of medication and regular follow up will be helpful to avoid morbid complication.

\section{References}

1. Haque KHM: 18th annual convention \& scientific session, Association of Physicians of Bangladesh (APB); HYPERTENSION: BANGLADESH PERSPECTIVE, 13th May, 2007. AQM NURUL HUQ MEMORIAL ORATION.

2. U.S. Department of Health \& Human Services, National Heart, Lung \& Blood Institute. National High Blood Pressure ducation Program. Available at: http://www.nhlbi.nih.gov/about/nhbpep/index.htm. Accessed March 5, 2003.

3. Roccella EJ, Kaplan NM. Interpretation \& evaluation of clinical guidelines. ln: lzzo .JL Jr, Black HR, eds. Hypertension Primer. Dallas, TX, American Heart Association, 2003;126:126-7.

4. National High Blood Pressure Education Program. The sixth report of the Joint National Committee on Prevention, Detection, Evaluation, and Treatment of High Blood Pressure. Arch Intern Med. 1997; 157: 2413- 46.

5. Sheps SG, Roccella EJ. Reflections on the sixth report of the Joint National Committee on Prevention, Detection, Evaluation, and Treatment of Hioh Blood Pressure Curr HypertensRep. 1999; 1: 342- 5.

6. Vasan RS, Larson MG, Leip EP, et al. Assessment of frequency of progression to hypertensionin nonhypertensive participants in the Framingham Heart Study: A cohort study. Lancet. 2001; 358: 1682- 6.

7. Vasan RS, Beiser A, Seshadri S, et al. Residual lifetime risk for developing hypertension in middle-aged women \& men: The Framingham Heart Study. JAMA.2002; 287: 1003- 10 .

8. Chobanian AV et al. The seventh report of the Joint National Committee on Prevention, Detection. Evaluation and Treatment of High Blood Pressure The JNC 7 Report. JAMA May 21. 200 3-Vol; 289, No. 19, Page- 2560. www.jama.com.

9. BHS (British Hypertension Society), NHS-National Institute for Health and Clinical Excellence (NICE). PRESS RELEASE, NICE 2006/028. Issued 26 June, 2006. nice@nice.org.uk, www.nice.org.uk.

10. Gordon H, Williams, Approach to the patient with hypertension. Harrison's principles of internal medicine, Mc Graw Hill.2001; 211-214. 
11. Basher A. Dissertation on "Study of Risk factors for stroke" 1995: P. 78-90.

12. Deyangov C, Hadjidova I, Mincheva I. Prevalence of arterial hypertension among school teachers in Sofia, Rev Environ Health 1994; 10: 47-50.

13. Young LC, Kuller LH, Rutan G, Bunker C. Longitudinal study of blood pressure change and determinants from adolescence to middle age. The Dormot High School follow-up Study, 1957-1963 to 1989-1990. Am J Epidemiol 1993; 138:973-983.

14. Berlowitz DR et al. Inadequate management of blood pressure in hypertensive population. $N$ Engl J med 339:1967, 1998.

15. Cerasola G, Cottone S, Mule G, Nardi E, Manano MT, Andronico G, Contorno A, Li Vecchi M, Galione P, Renda
F, Piazza G, Volpe V, Lisi A, Ferrara L, Panepinto N \& Riccobene R (1996). Microalbuminuria, renal dysfunction and cardiovascular complication in essential hypertension. Journal of Hypertension, 14: 915-920.

16. Bloomfield P, Brudbur A, Grubb NR. New by DE. Cardiovascular disease. In: Boon NA, Colledge NR, Walker BR, Hunder John A, editors. Davidson's principles and practice of medicine, 20th edition, Edinburgh: ELBS/ Churchill Livingstone 2006:519-646.

17. Ullah W. Hypertension in a mixed community. Bangladesh Res Coun Bill 1976; 11:95-99.

18. Najmul A. Dissertation on "Prevalence of hypertension in the low income group of people in the community"- A study of 201 people more than 30 years of age. 1995:p- 66. 